\title{
Contaminação microbiológica de ambientes e de superfícies em restaurantes comerciais
}

\author{
Microbiological contamination \\ of environments and surfaces at commercial restaurants
}

Ana Íris M endes Coelho ${ }^{1}$

Regina Célia Rodrigues M iranda M ilagres ${ }^{1}$

Joice de Fátima Laureano $M$ artins $^{1}$

Raquel M onteiro Cordeiro de Azeredo ${ }^{1}$

Ângela M aria Campos Santana ${ }^{1}$

${ }^{1}$ Departamento de N utrição eSaúde, Universidade Federal deViçosa. Av. PH Rolfs s/n, Campus Universitário. 36571-000 Viçosa MG.

aicoelho@ufv.br
Abstract This study was carried out to provide subsidies for sanitary actions applied to manipulators, environments and surfaces, assessing levels of microbiological contamination in three commercial restaurants ( $A, B$ and $C$ ) in Viçosa, $\mathrm{Mi}$ nas Gerais State. Microbiological analysis were performed for presumptive counting of $\mathrm{Ba}$ cillus cereus and mesophilic aerobic bacteria on surfaces of stainless steel benches, equipments, utensils and hands of the manipulators (swab technique), and air (simple sedimentation). It was observed expressive contamination by mesophilic aerobic bacteria in the samples examined, exceeding limits proposed by the A PH A (American Public Health Association). M esophilic aerobic microorganisms were detected in $100 \%$ of air samples, with counts ranging from $4.1 \times 10^{1} \mathrm{CFU} / \mathrm{cm}^{2} /$ week to $1.1 \times 10^{3} \mathrm{CFU} / \mathrm{cm}^{2} /$ week. Typical colonies of B. cereus were detected in $19 \%$ of all air samples, and the presence of such colonies was observed in all restaurants in levels that reached 2.1 $x 10^{1} \mathrm{CFU} / \mathrm{cm}^{2} /$ week. In surfaces and hands examined it was also possible to isolate typical colonies of the pathogen in all restaurants. The sanitary situation of theenvironmentsstudied requires interventions to reduce risks of great magnitude, concerning the occurrence of foodborne diseases. Key words Restaurants, Environment, Food microbiology
Resumo Essetrabalho foi desenvolvido para fornecer subsídios para ações sanitárias aplicáveis a manipuladores, ambientes e superfícies, avaliando a contaminação microbiológica em três restaurantes comerciais (A, B e C) em Viçosa (M G). Foram realizadas análises microbiológicas para contagem presuntiva de Bacillus cereus e mesófilos aeróbios em superfícies de bancadas, equipamentos, utensílios e mãos de manipuladores (técnica de swab) e ar (sedimentação simples). Constatou-se expressiva contaminação por mesófilos aeróbios nas amostras examinadas, excedendo os limites propostos pela APHA (American Public $\mathrm{H}$ ealth Association). Estes microrganismos foram detectados em $100 \%$ das amostras de ar, com contagem variando de 4,1 x 101 $\mathrm{UFC} / \mathrm{cm}^{2} /$ semana a $1,1 \times 10^{3} \mathrm{UFC} / \mathrm{cm}^{2} / \mathrm{semana}$. Colônias típicas de $B$. cereus foram detectadasem $19 \%$ do total deamostras de ar, sendo a presença deste tipo de colônias observada em todos os restaurantes e a contagem máxima foi de 2,1 $\times 10^{1} \mathrm{U} \mathrm{FC} / \mathrm{cm}^{2} / \mathrm{semana}$. Nas superfícies e mãos examinadas, também foi possível isolar colônias típicas desse patógeno, em todos os restaurantes. A situação sanitária dos ambientes pesqui sados requer intervenções para reduzir riscos de grande magnitude, no que se refere à ocorrência de doenças de origem alimentar.

Palavras-chave Restaurantes, Ambiente, Microbiologia de alimentos 
Introdução

Em serviços de alimentação, a garantia de qualidadeé prioritária, uma vez quea cada dia seacentua o hábito de realizar refeições fora de casa. Acompanhando essa tendência, os restaurantes do tipo self-service que comercializam as refeições por peso constituem um segmento do setor dealimentação em expansão no nosso meio. Esse tipo de serviço apresenta vantagens para o consumidor, tais como variedade de opções, rapidez deatendimento ecustos em geral mais acessíveis. Entretanto, alguns fatores preocupam os profissionais da área de alimentação, tais como a insegurança dos alimentos, pelo maior tempo de exposição em temperaturas inadequadas, e a falta de adequada educação alimentar da clientela na escolha dos alimentos. ${ }^{1}$.

Em áreas de processamento dealimentos, são fontes reconhecidas de aerossóis a atividade de pessoal, os drenos do piso, os sistemas de ventilação, a comunicação entresetores distintos, os alimentos derramados, os sistemas de transporte, entre outras². Assim, a avaliação da contaminação microbiológica do ar em locais derisco éconsiderada um passo básico em direção à prevenção ${ }^{3}$.

Outro fator que requer um maior controle para garantir a segurança dos alimentos é o manipulador de alimentos; sendo doente ou portador assintomático, éresponsável por até $26 \%$ dos surtos de enfermidades bacterianas veiculadas por alimentos, por apresentar hábitos higiênicos inadequados, ou ainda pela utilização de métodos anti-higiênicos na preparação de alimentos. Equipamentos e utensílios com higienização deficiente também têm sido responsáveis por surtos de doenças de origem alimentar; portanto, devem passar constantemente por uma avaliação microbiológica para evitar a contaminação dos alimentos produzidos4.

Dentre as bactérias mais comuns que podem levar à ocorrência de doenças de origem alimentar, encontra-se Bacillus cereus, microrganismo presente em locais diversificados, como solo, ve getação, água e pêlos de animais $5^{5}$. As intoxicações alimentares causadas por esse patógeno, capaz de formar esporos, são favorecidas quando há abuso de tempo-temperatura, propiciando a multiplicação do microrganismo e contagens mai ores que $10^{5} \mathrm{UFC} / \mathrm{g}^{6}$.

0 presente trabalho teve como objetivo fornecer subsídios para ações sanitárias aplicáveis a manipuladores, ambientes esuperfícies, avaliando níveis de contaminação microbiológica em restaurantes. Especificamente, a propostafoi ava- liar a contaminação por microorganismos me sófilos aeróbios e do grupo B. cereus no ar, bem como em superfícies de bancadas, utensílios, equipamentos e mãos de manipuladores, em restaurantes comerciais de maior demanda de clientes, no município de $V$ içosa (M G).

\section{Material e métodos}

0 trabal ho foi realizado em restaurantes comerciais do tipo self-service, na cidade de Viçosa (M G). As análises microbiológicas foram desenvolvidas no Laboratório de Higiene de Alimentos do Departamento de Nutrição e Saúde da Universidade Federal deViçosa.

\section{Seleção dos restaurantes e definição dos pontos para coletas de amostras}

Foram escolhidos intencionalmente os restaurantes que ofereciam maior número de refeições, tendo em vista que possíveis fal has no processo destas unidades podem atingir grande parcela de indivíduos. Três restaurantes foram selecionados aleatoriamente para participar do estudo, entre os cinco de maior demanda queaceitaram participar da pesquisa, nomeados como restaurantes $A, B$ e C.

A partir do conhecimento das diferenças entre os fluxos de produção, a organização do trabalho, as dimensões e as atividades desenvolvidas em cada um dos restaurantes, foram definidos os pontos de coleta de amostras com base na atividade predominante do local, ainda que frequentemente duas ou mais tarefas distintas fossem executadas em áreas comuns, procurando-se obter abrangência que garantisse a representatividade das áreas de cada unidade de estudo de forma a diminuir as variáveis que pudessem influenciar nos resultados e possi bilitar uma melhor interpretação dos dados.

Em cada restaurante, para a coleta das amostras de ar e de superfícies de bancadas, foram fixadas duasáreas, a de preparo de vegetaise a de carnes, e elegeu-se um terceiro ponto em função da estrutura de cada local, que correspondeu ao setor de apoio no restaurante $A$, de frutas no restaurante $B$ e de massas no restaurante $C$.

Os utensílios examinados foram facas de manipulação, tábuas de altileno e cuba de aço inoxidável do balcão de distribuição, escolhidos em função do alto risco de causar toxinfecção?. Os equipamentos foram geladeira, picador manual de vegetais e liquidificador, selecionados 
também em função do risco de causar toxinfecção e por serem equipamentos que estavam disponíveis em todos os restaurantes avaliados. As amostras foram coletadas em áreas dos utensílios e equipamentos que tinham contato com os alimentos.

Foram selecionados dois manipuladores de alimentos, aleatoriamente, dos setores de vegetais e de carnes e cocção, para coleta de amostras das mãos, em cada restaurante.

Foram realizadas três repetições de coleta em diferentes ocasiões e, a cada repetição, as amostras dear, desuperfícies debancadas, de equipamentos e de utensílios foram tomadas em duplicata.

Coletas das amostras de ar

e análises microbiológicas

As amostras de ar foram coletadas antes do início do preparo das refeições e após a higienização rotineira do ambientedetrabalho, por meio datécnica desedimentação simples, em placas de Petri contendo meios de cultivo apropriados, conforme metodologia proposta por Evancho et al. ${ }^{8}$. As placas de Petri colocadas sobre as bancadas, nos pontos previamente selecionados, foram abertas e expostas por quinze minutose, em seguida, foram acondicionadas em caixas isotérmicas contendo gelo e transportadas imediatamente para análise no laboratório.

A técnica de sedimentação simples é classificada como classe D pela APHA, ou seja, uma metodologia que já foi considerada padrão, mas que está sendo substituída por técnicas mais eficientes. Embora a técnica de sedimentação simples não recupere alguns tipos de microrganismos presentes no ar, éuma técnica recomendada por um órgão reconhecido internacionalmente e, por isso, é útil na avaliação de ambientes nos restaurantes industriais $9^{9,10}$.

Para a pesquisa de bactérias do grupo BaciIlus cereus, as placas continham ágar $M$ anitolPolimixina B (ágar M YP- M erck $\circledast$ ). Apósa incubação a $30^{\circ} \mathrm{C}$ por 18 a 24 horas, foram feitas as contagens de exemplares de bactérias do grupo de B. cereus ${ }^{5}$. A contagem de microrganismos mesófilosaeróbios foi realizada em placascontendo Plate Count Agar (PCA - M erck $®$ ), apósa incubação por 24 a 48 horas $^{11}$. Os resultados das contagens foram expressos em Unidades Formadoras de Colônia/ $\mathrm{cm}^{2} /$ semana (UFC/ $\mathrm{cm}^{2} /$ semana).
Análises microbiológicas de bancadas, equipamentos e utensílios e mãos e manipuladores

Asanálises da superfíciede bancada, utensílios, equipamentos e mãos de manipuladores foram desenvolvidas por meio da técnica do swab, adotando procedimento proposto pela American $\mathrm{Pu}$ blic Health Association (APHA), descrito por Evancho et al. ${ }^{8}$. Para o liquidificador, foi utilizado método de lavagem com $10 \mathrm{~mL}$ de solução peptonada esterilizada e o próprio equipamento para agitação por trinta segundos com posterior recolhimento da amostra em tubo de ensaio esterilizado.

As amostras foram levadas para o laboratório, imediatamente após as coletas, onde foram preparadas as diluições decimais para semeadura em placas de Petri contendo PCA, para a contagem de mesófilos aeróbios, e ágar MYP para espécies do grupo de Bacillus cereus.

\section{Resultados ediscussão}

Avaliação da presença de microrganismos mesófilos aeróbios no ar

No levantamento realizado, $100 \%$ das amostras de ar revelaram contaminações por microrganismos mesófilos aeróbios, superiores ao limite de $30 \mathrm{UFC} / \mathrm{cm}^{2} /$ semana, proposto pela $\mathrm{Na}$ tional Aeronautics and Space Administration (NASA), endossado pela APH ${ }^{8}$. No restaurante $C$, na bancada de preparo de carnes, observouse uma contagem de mesófilos da ordem de $10^{3}$ $\mathrm{UFC} / \mathrm{cm}^{2} /$ semana, mais de trinta vezes superior ao preconizado pela APHA (Tabela 1). Contagens semel hantes foram relatadas por Silva ${ }^{12}$ no setor de pré-preparo de vegetais, em restaurantes industriais. Azeredo et al. ${ }^{13}$ identificaram em Unidades deAlimentação eN utrição (UAN) maior contaminação nos setores de cocção e distribuição. Alto percentual de contaminação também foi revelado por Andrade et al. ${ }^{4}$, que encontraram contagens acima daquele limiteem $81,5 \%$ dos ambientes, entre doze restaurantes industriais da Zona da M ata mineira. Tomich et al. ${ }^{14}$ registraram $85,7 \%$ de amostras com contagens superiores ao limite proposto pela APHA em indústrias de pão de queijo.

A qualidade do ar em unidades de processamento dealimentos pode não afetar diretamente a segurança microbiológica, ou a manutenção da qualidade, em se tratando de alimentos pouco perecíveis. No entanto, alimentos mais susce- 
Tabela 1. Contaminação do ar por microrganismos mesófilos aeróbios, em três restaurantes self-service na cidade de Viçosa (M G).

\begin{tabular}{|c|c|c|c|}
\hline \multirow{2}{*}{ Superfícies de bancadas a } & \multicolumn{3}{|c|}{ UFC $/ \mathrm{cm}^{2} /$ semana } \\
\hline & \multicolumn{3}{|c|}{ Restaurantes } \\
\hline & A & B & C \\
\hline & \multicolumn{3}{|c|}{ Variação de três coletas } \\
\hline Pré-preparo de vegetais & $4,1 \times 10^{1}-1,8 \times 10^{2}$ & $1,1 \times 10^{2}-1,9 \times 10^{2}$ & $2,5 \times 10^{2}-5,8 \times 10^{2}$ \\
\hline Apoio, frutas e massas & $4,1 \times 10^{1-} 2,3 \times 10^{2}$ & $1,4 \times 10^{2}-1,6 \times 10^{2}$ & $4,8 \times 10^{2}-6,6 \times 10^{2}$ \\
\hline Pré-preparo de carnes & $1,3 \times 10^{2}-7,0 \times 10^{2}$ & $1,2 \times 10^{2}-3,4 \times 10^{2}$ & $6,5 \times 10^{2}-1,1 \times 10^{3}$ \\
\hline
\end{tabular}

a Examinada pela técnica de sedimentação simples.

tíveis à deterioração são particularmente sensíveis à contaminação por microrganismos transportados pelo ar9.

0 número de microrganismos obtidos nas amostras de ar do presente estudo, pelo método desedimentação, variou entre $4,1 \times 10^{1} \mathrm{UFC} / \mathrm{cm}^{2} /$ semana e $1,1 \times 10^{3} \mathrm{UFC} / \mathrm{cm}^{2} /$ semana. A alta contaminação pode ser decorrente da falta de barreira física (os restaurantes em estudo não apresentavam separações de área), fato associado ao aumento da contaminação do $\operatorname{ar}^{15}$. 0 fato dos dados terem sido coletados durante o horário de produção das refeições nos restaurantes também pode ter contribuído para a elevada contaminação detectada no ar. Além disso, o número de microrganismos presentes no ar pode ser influenciado pela temperatura e pela umidade. Embora não tenham sido pesquisados no presente estudo, esses fatores também podem ter contribuído para os resultados encontrados. Salustiano et al. ${ }^{16}$, analisando contagens de bactérias mesófilas aeróbias no ar em áreas de processamento deindústria de laticínios, verificaram que os resultados não foram afetados pela variação da temperatura; entretanto, foram influenciados pela umidade do ar.

As variabilidades de contagens de microrganismos mesófilos aeróbios, observadas entre as diversas coletas, considerando que esses microrganismos são indicadores do processo dehigienização. dão suporte para a hipótese de que os restaurantes careçam de falta de padronização nos procedimentos dehigienização, podendo comprometer a qualidadehigiênico-sanitária dosalimentos. A pesar deste grupo de microrganismos não oferecer um risco direto à saúde, sua presença excessiva no ambiente pode favorecer a contaminação dos alimentos presentes na área de processamento e consequentemente sua deterioraçãa ${ }^{17}$.

Avaliação da presença de bactérias do grupo Bacillus cereus no ar

Os valores encontrados evidenciaram desde a não detecção (ND) até $2,1 \times 10^{1} \mathrm{UFC} / \mathrm{cm}^{2} / \mathrm{se}$ mana (Tabela 2), sendo que a presença foi detectada em todos os setores pesquisados. Essa expressiva presença de bactérias do grupo de B. cereus indica a importância de medidas de controle, uma vez que este patógeno é capaz de formar esporos que são particularmente resistentes ao calor, à desidratação e à luz UV, favorecendo a sua disseminação no ambiente e também sua adesão às diferentes superfícies ${ }^{18,19}$.

Osníveis de contaminação apresentados neste estudo corroboram os encontrados por Milagres ${ }^{20}$, que também mostrou que todas as amostras de ar analisadas na pesquisa de B. cereus revelaram contaminações inferiores ao limite de $30 \mathrm{UFC} / \mathrm{cm}^{2} / \mathrm{sem} a n a$ para mesófilos aeróbios recomendados pela $\mathrm{APHA}^{8}$. No entanto, adotar esse padrão para bactérias do grupo B. cereus exige bastante tolerância, visto que se trata de um patógeno reconhecido eque frequentemente tem sido envolvido em doenças de origem alimentar ${ }^{21}$. A ausência de recomendações específicas dificulta a avaliação dos resultados obtidos.

Considerando que as células vegetativas de bactérias costumam estar presentes em menor número, no ar, em comparação com esporos bacterianos e defungo, em virtude de não sobreviverem por longo período em substratos iner- 
tes ${ }^{22}$, os resultados obtidos podem não revelar completamente o perigo associado a que os consumidores destes restaurantes estão expostos, tendo em vista que a presença de esporos de $B$. cereus não foi avaliada neste estudo. Além disso, a contaminação real pode ter sido subestimada, em razão do uso de meio de cultivo seletivo e do estado de estresse dos microrganismos sob a forma de aerossóis, o que pode dificultar a recupe ração e o crescimento do patógeno ${ }^{9}$.

A presença de bactérias do grupo $B$. cereus no ar foi verificada em todos os restaurantes, em cinco $(18,51 \%)$ das 27 amostras coletadas. Resultado semelhantefoi relatado por M osso et al. ${ }^{23}$, que encontraram o microrganismo em $24 \%$ das 307 amostras coletadas em doze serviços de alimentação na I tália. Entretanto, percentuais mais elevados foram descritos por outros autores. M ilagres ${ }^{20}$ encontrou $61,8 \%$ das amostras de ar contaminadas com o patógeno, em restaurantes comerciais da cidade de Viçosa (M G), enquanto Soares et al. ${ }^{24}$ revelaram $84,4 \%$ das amostras de ar ambiente contaminadas por B. cereus em restaurantes institucionais.

Avaliação da presença de microrganismos mesófilos aeróbios nas superfícies de bancadas, utensílios e equipamentos e mãos de manipuladores

Foram observadas contagens el evadas em superfícies de bancadas, utensílios e equipamentos (Tabela 3), especialmente se as recomendações da APH A forem tidas como referência, uma vez que essa preconiza uma contagem de até 2 UFC/ $\mathrm{cm}^{2}$ para superfícies debancadas e 100 UFC/ utensílios ou área amostrada de equipamentos ${ }^{8}$.
A totalidade das amostras de superfícies de bancadas eutensílios examinados foi encontrada fora desse limite recomendado, enquanto nos equipamentosfoi verificado um percentual de inadequação de $71 \%$. Considerando os padrões estabelecidos pela APHA, 85,7\% dos utensílios e 93,6\% equipamentos analisados no estudo de Tomich et al. ${ }^{14}$, em uma indústria de pão dequeijo, também estavam inadequados.

A contagem de mesófilos em utensílios atingiu valor na ordem de $10^{8} \mathrm{e}$, em equipamentos, contagem de $10^{7}$, valores muito superiores ao recomendado pela APHA, o que demonstra a necessidade de medidas de controle higiênicosanitários urgentes.

Pela dificuldade de adequação ao padrão americano, alguns pesquisadores e instituições admitem contagens superiores, por exemplo, Silva Júnior ${ }^{15}$, que preconiza uma contagem menor ou igual a $50 \mathrm{UFC} / \mathrm{cm}^{2}$ para equipamento, utensílios ou superfície em razão principalmente das condições de temperatura ambiental no Brasil. Verifica-se que, em superfícies de bancadas, 0 resultado de $0 \%$ de adequação passaria para 15,4\% para microrganismos mesófilos aeróbios. Ainda assim, os resultados permanecem insatisfatórios quanto à segurança dessas superfícies no aspecto sanitário, podendo comprometer a qualidade microbiológica dos alimentos que entram em contato direto com as mesmas, especialmente se o alimento for consumido cru ou sea temperatura de aquecimento não atinge limites capazes de inativar células vegetativas ou toxinas eventualmentepresentes.

As maiores contagens foram registradas nas bancadas dos setores de pré-preparo de vegetais e de carnes, atingindo a ordem de $10^{5} \mathrm{UFC} / \mathrm{cm}^{2}$.

Tabela 2. Contaminação do ar por bactérias do grupo Bacillus cereus, em três restaurantes self-service na cidade de Viçosa ( $M G$ ).

\begin{tabular}{lccc}
\hline \multirow{2}{*}{ Superfícies de bancadas a } & \multicolumn{3}{c}{ UFC/ $\mathrm{cm}^{2} /$ semana } \\
\cline { 2 - 4 } & $\mathrm{A}$ Restaurantes \\
\cline { 2 - 4 } & \multicolumn{3}{c}{ Variação de três coletas } \\
\cline { 2 - 4 } Pré-preparo de vegetais & $\mathrm{ND}$ & $\mathrm{ND}-5,2 \times 10^{\mathrm{b}}$ & $\mathrm{ND}-5,7 \times 10^{0}$ \\
Apoio, frutas e massas & $\mathrm{ND}-1,0 \times 10^{1}$ & $\mathrm{ND}$ & $\mathrm{ND}$ \\
Pré-preparo de carnes & $\mathrm{ND}$ & $\mathrm{ND}-2,1 \times 10^{1}$ & $\mathrm{ND}$ \\
\hline
\end{tabular}

${ }^{a}$ Examinada pela técnica de sedimentação simples; ${ }^{b} \mathrm{~N}$ ão detectado. 
Tabela 3. Contaminação de superfícies de bancadas, utensílios, equipamentos e mãos de manipuladores por microrganismos mesófilos aeróbios, em três restaurantes self-service na cidade de Viçosa (MG).

\begin{tabular}{|c|c|c|c|}
\hline & \multicolumn{3}{|c|}{ Restaurantes } \\
\hline & A & $\mathrm{B}$ & $\mathrm{C}$ \\
\hline Superfícies de bancadas a & \multicolumn{3}{|c|}{$\begin{array}{l}\text { Variação de três coletas } \\
\text { U FC/ } / \mathrm{cm}^{2}\end{array}$} \\
\hline Pré-preparo de vegetais & $4,0 \times 10^{0}-5,2 \times 10^{3}$ & $3,5 \times 10^{4}-1,7 \times 10^{5}$ & $3,1 \times 10^{1}-1,9 \times 10^{5}$ \\
\hline Apoio, frutas e massas & $9,4 \times 10^{2}-2,2 \times 10^{3}$ & $1,6 \times 10^{3}-2,8 \times 10^{4}$ & $3,2 \times 10^{1}-3,2 \times 10^{2}$ \\
\hline Pré-preparo de carnes & $1,1 \times 10^{3}-5,7 \times 10^{4}$ & $2,4 \times 10^{4}-7,8 \times 10^{5}$ & $9,9 \times 10^{2}-2,5 \times 10^{4}$ \\
\hline & \multirow{2}{*}{\multicolumn{3}{|c|}{$\begin{array}{l}\text { Variação de três coletas } \\
\text { UFC/utensílio }\end{array}$}} \\
\hline Utensílios a & & & \\
\hline Tábua de altileno & $7,0 \times 10^{2}-3,1 \times 10^{7}$ & $8,6 \times 10^{6}-2,7 \times 10^{7}$ & $7,1 \times 10^{5}-1,9 \times 10^{8}$ \\
\hline Faca de manipulação & $3,6 \times 10^{4}-7,4 \times 10^{5}$ & $3,3 \times 10^{4}-1,1 \times 10^{7}$ & $1,6 \times 10^{6}-3,6 \times 10^{7}$ \\
\hline \multirow[t]{2}{*}{ Cuba de aço inoxidável } & $3,5 \times 10^{2}-5,5 \times 10^{5}$ & $1,7 \times 10^{3}-6,3 \times 10^{6}$ & $7,6 \times 10^{5}-1,2 \times 10^{6}$ \\
\hline & \multicolumn{3}{|c|}{$\begin{array}{l}\text { Variação de três coletas } \\
\text { UFC/equipamento (ou } \mathrm{cm}^{2} \text {, na geladeira) }\end{array}$} \\
\hline \multicolumn{4}{|l|}{ Equipamento } \\
\hline Picador de vegetais ${ }^{a}$ & $2,2 \times 10^{7}-8,3 \times 10^{7}$ & $5,5 \times 10^{4}-1,8 \times 10^{7}$ & $1,1 \times 10^{3}-1,8 \times 10^{6}$ \\
\hline Liquidificador ${ }^{b}$ & $2,2 \times 10^{6}-2,6 \times 10^{6}$ & $3,2 \times 10^{4}-1,4 \times 10^{5}$ & $1,4 \times 10^{5}-1,9 \times 10^{6}$ \\
\hline 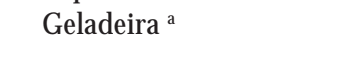 & $9,8 \times 10^{0}-1,2 \times 10^{3}$ & $1,9 \times 10^{4}-1,7 \times 10^{5}$ & $1,0 \times 10^{3}-4,2 \times 10^{4}$ \\
\hline M anipulador a & \multicolumn{3}{|c|}{$\begin{array}{l}\text { Variação de três coletas } \\
\text { UFC/mão }\end{array}$} \\
\hline Vegetais & $8,0 \times 10^{2}-6,0 \times 10^{5}$ & $5,0 \times 10^{4}-1,2 \times 10^{6}$ & $2,3 \times 10^{3}-2,2 \times 10^{4}$ \\
\hline Carnes e cocção & $1,1 \times 10^{5}-1,5 \times 10^{6}$ & $1,5 \times 10^{4}-3,9 \times 10^{4}$ & $4,7 \times 10^{3}-7,2 \times 10^{6}$ \\
\hline
\end{tabular}

a Examinados pela técnica deswab; b Examinado pelo método de lavagem.

Em relação à contaminação das mãos de manipuladores, foram encontradas amostras com valoresna ordem de $10^{6} \mathrm{UFC} /$ mão para microrganismos mesófilos aeróbios, em 17\% dos manipuladores do setor de carnes e de cocção e em $5 \%$ de manipuladores do setor de vegetais. No presente estudo, os swabs foram friccionados nas mãos dos manipuladores após higienização das mesmas e a contaminação encontrada demonstrou queo processo dehigienização foi deficiente, indicando que as mãos analisadas podem ser fontes de contaminação nestes restaurantes. Soares et al. ${ }^{24}$ relataram a importância do uso de agente bactericida apropriado, no processo de higienização das mãos, evidenciando o efeito de solução sanificanteà base de iodo, na concentração de 1\%.

$\mathrm{Na}$ contagem total de microrganismos me sófilos aeróbios em mãos de manipuladores, um estudo realizado em Serviço de Alimentação do Rio Grande do Sul, detectou que $100 \%$ das amostras ultrapassaram o limite de $2 \times 10^{3} \mathrm{UFC} /$ mão, sugerido por Visier de acordo com Sacool ${ }^{25}$.

Entretanto, estudo de Andrade et al. ${ }^{4}$ revelou resultados semelhantes ao da presente pesquisa com um percentual de $13,2 \%$ das amostras na ordem $10^{6} \mathrm{UFC} / \mathrm{mão}$. Uma contagem ainda mais expressiva foi constatada por Almeida et al. ${ }^{26}$, chegando a valores na ordem de $10^{7} \mathrm{UFC} /$ mão. Tomich et al. ${ }^{14}$, em $59 \%$ das amostras das mãos de funcionários, observaram contagens de mesófilos superiores a $10^{5} \mathrm{UFC} / \mathrm{mão}$. Esses estudos também demonstraram a importância dos manipuladores de alimentos como causas potenciais de contaminação dos alimentos nas unidades analisadas. 
Avaliação da presença de bactérias do grupo Bacillus cereus nas superfícies de bancadas, utensílios e equipamentos e mãos de manipuladores

A presença de bactérias do grupo $B$. cereus foi observada em $42 \%$ de um total de 78 amostras obtidas de superfícies de bancada, equipamentos e utensílios. A detecção desse microrganismo requer o uso de meios sel etivos e sua presença deve ser interpretada à luz da excepcional resistência de suas formas esporuladas e da capacidade de multiplicação das células em diferentes substratos alimentares. A bactéria pode ser transferida para os alimentos a partir de diferentes fontes e aí sobreviver, em forma de esporos, a tratamentos térmicos que reduzem a população competitiva, o quelheproporciona condições ideais de multiplicação ${ }^{27}$.

As maiores contagens, no ambiente, foram encontrados em equipamentos e utensílios, sen- do verificado em cuba de aço inoxidável contagem de 1,2 x 104UFC/utensílio e, em picador de vegetais e liquidificador, contagem de 5,0 × $10^{2}$ UFC/equipamento (Tabela 4).

No presente estudo, $85 \%$ do total de amostras de bancadas analisadas apresentaram bactérias do grupo B. cereus. Percentuais inferiores foram observados por Milagres ${ }^{20}(53 \%)$, Soares ${ }^{24}$ (44,8\% ) e M endes et al. ${ }^{28}(27 \%)$, em amostras de superfícies de bancadas de restaurante contaminadas por B. cereus.

A presença de microrganismos do grupo $B$. cereus também foi verificada em bancada de prépreparo demassas no presenteestudo, sendo esse o único local onde o patógeno não foi relatado por $M$ endes et al..$^{28}$.

A legislação brasileira não estabelece limites para contagem de microrganismos em superfícies de processamento de alimentos. Considerando a recomendação de Silva Jr. ${ }^{15}$ de ausência de B. ce reusem $50 \mathrm{~cm}^{2}$ de superfícies de bancadas, equipa-

Tabela 4. Contaminação de superfícies de bancadas, utensílios, equipamentos e mãos de manipuladores por bactérias do grupo Bacillus cereus, em três restaurantes self-service na cidade de Viçosa (MG).

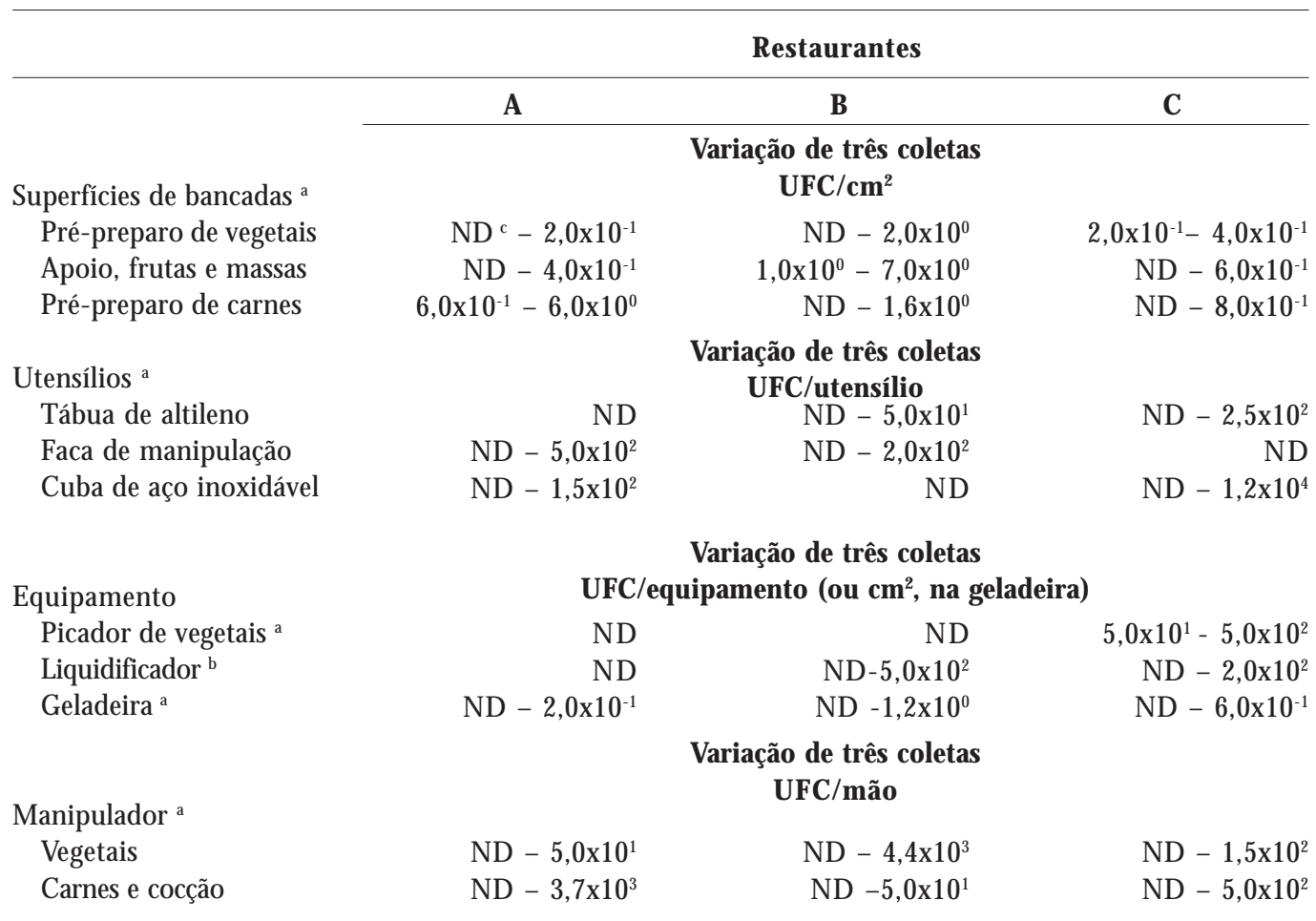

${ }^{a}$ Examinados pela técnica de swab; ${ }^{b}$ Examinado pelo método de lavagem; ${ }^{c} \mathrm{~N}$ ão detectado. 
mentos e utensílios de preparação, os resultados obtidos revelaram que em todos os restaurantes analisados essa recomendação não foi atendida, em pelo menos uma das coletas realizadas em superfícies de bancadas e de geladeira. Em relação aosutensílios, a ausência de bactérias do grupo $B$. cereus foi identificada em $69 \%$ das amostras.

Embora não exista padrão microbiológico para B. cereus em mãos, colônias típicas desse microrganismo foram encontradas, no presente estudo, até valores de $10^{3} \mathrm{UFC} /$ mão.

A partir desses dados, verifica-se que devem ser realizadas, de imediato, medidas eficazes de controle higiênico-sanitário para reduzir essa contaminação, pois a simples presença desse microrganismo revela a necessidade deintervenções devido ao potencial de multiplicação ao ser transferido aos alimentos, podendo colocar em risco a saúde dos usuários. A identificação dos principais locais como origens potenciais do microrganismo ou de seus esporos deve ser considerada para evitar ou reduzir a contaminação dos alimentos na linha de processamento, como relatam alguns pesquisadores ${ }^{29}$. Segundo Soto et al. ${ }^{6}$, a redução do risco de intoxicações por $B$. cereus poderia ocorrer se 0 ambiente de manipulação dos alimentos fosse controlado.

N este trabalho, ficou evidente a importância da contaminação das superfícies pesquisadas e do ar ambiente como fonte potencial de micror- ganismos para os alimentos nos restaurantes estudados, podendo originar alterações indesejáveis nos alimentos produzidos e possibilitar veiculação de patógenos, especialmente a partir daqueles pontos onde foram identificadas contagens mais expressivas. Esses pontos de contaminação podem permitir a contaminação cruza$\mathrm{da}$, se não forem adotadas rigorosas medidas preventivas. Uma vez que a contaminação pode ocorrer nas diversas etapas de produção de re feições, ressalta-se a importância da adoção de boas práticas de fabricação nos serviços de alimentação estudados, de forma a favorecer condições seguras na produção das refeições.

\section{Conclusões}

Considerando que a contaminação do ar, de superfícies e de mãos de manipuladores dealimentos por microrganismos mesófilos aeróbios e por bactérias do grupo B. cereus pode indicar condições de higi ene carentes demelhorias, os resultados observados sugerem que medidas de controle devam ser implementadas nos restaurantes estudados. Verifica-se, ainda, a necessidade de regulamentação no Brasil que estabeleça padrões microbiológicos para ar, superfícies e mãos de manipuladores de alimentos. 


\section{Colaboradores}

AIM Coelho e RCRM M ilagres trabalharam na concepção e orientação da pesquisa e redação do artigo; JFL M artins trabalhou na pesquisa e redação do artigo; RM C Azeredo trabalhou na orientação e análise dos dados da pesquisa; AMC Santana trabalhou na concepção, orientação da pesquisa e coordenação do projeto de pesquisa que deu origem ao presente artigo.

\section{Agradecimentos}

À Fundação de Amparo à Pesquisa do Estado de Minas Gerais (FAPEMIG), pelo apoio financeiro ao Projeto Segurança alimentar em serviços de alimentação: uma proposta para avaliação das boas práticas de fabricação e da contaminação, de superfícies de bancada, de equipamentos, de utensílios e de mãos de manipuladores.

\section{Referências}

1. Lima JX, Oliveira LF. O crescimento do restaurante self-service: aspectos positivos e negativos para 0 consumidor. Rev Hig Aliment 2005; 19:45-53.

2. Salustiano VC. Avaliação da microbiota do ar de ambientes de processamento em uma indústria de laticínios e seu controle por agentes químicos [tese]. Viçosa (M G): U niversidade Federal de Viçosa; 2002.

3. Pasquarela C, Pitzurra O, Savino A. The index of microbial air contamination. J Hosp Infect. 2000; 46:241-256.

4. Andrade NJ, Silva RMM , Brabes KCS. Avaliação das condições microbiológicas em unidades de alimentação e nutrição. Ciênc Agrotec. 2003; 27(3):590-596.

5. Bennett RW, Belay NB. Bacillus cereus. In: Downes FP, Ito K, editors. Compendium of methods for the microbiological examination of foods. $4^{\text {th }} \mathrm{ed}$. Washington, D.C.: APHA; 2001. p. 311-316.

6. Soto FRM, Risseto MR, Fonseca YSK, Dias AM G. Toxinfecção alimentar por Bacillus cereus: relato de caso. Rev Hig Aliment 2005; 19:33-36.

7. Silva Jr. EA. Manual de controle higiênico-sanitário em alimentos. 6ạ ed. São Paulo: Varela; 2005.

8. Evancho GM, Sveum WH, Moberg LJ, Frank JF. $M$ icrobiological M onitoring of the Food Processing Environment. In: Downes FP, Ito K, editors. Compendium of methods for the microbiological examination of foods. $4^{\text {th }}$ ed. Washington, D.C.: APHA; 2001. p. 25-36.

9. Sweum WH, Moberg LJ, Rude R, Frank JF. Microbiological monitoring of the food processing environment. In: Vanderzant C, Splittstoeser DF, editors. Compendium of $\mathrm{M}$ ethods for the M icrobiological Examination of Foods. $3^{\text {rd }}$ ed. Washington, D.C.: APHA; 1992. p. 51-75.

10. Salustiano VC, Brabes KCS, Andrade, NJ. Ar de ambientes de processamento de um abatedouro: avaliação e controle por agentes químicos sanificantes. Rev Nac Carne 2001; (25)293:54-152.

11. Morton RD. Aerobic Plate Count. In: Downes FP, Ito $\mathrm{K}$, editors. Compendium of methods for the microbiological examination of foods. $4^{\text {th }}$ ed. Washington, D.C.: APHA; 2001. p. 63-67.

12. Silva RM M. Especificações microbiológicas para ambientes, manipuladores e equipamentos em restaurantes industriais [tese]. Viçosa (MG): Universidade Federal de Viçosa; 1996.

13. Azeredo RMC, Soares CM, Kuaye AY, Leitão MFF. Detecção e avaliação da incidência de Bacillus cereus em amostras de ar, coletadas em unidades de alimentação e nutrição. Rev Hig Aliment 2001; 15(80/81):195.

14. Tomich RGP, Tomich TR, Amaral CAA, Junqueira RG, Pereira AJG. M etodologia para avaliação das boas práticas de fabricação em indústrias de pão de queijo. Ci Tecnol Aliment 2005; 25(1):115-120.

15. Silva Jr. EA. M anual de controle higiênico-sanitário em alimentos. 4a ed. São Paulo: Varela; 2001.

16. Salustiano VC, Andrade NJ, Brandão SCC, Azeredo RM C, Lima SAK. Microbiological air quality of processing areas in a airy plant as evaluated by the sedimentation technique and a One-Stage Air Sampler. Braz J Microbiol 2003; (34): 255-259. 
17. Leitão MFF, Hagler LCSM, Hagler AN, Menezes TJB. Tratado de microbiologia. São Paulo: Manole; 1988.

18. Pirttijärvi TSM, Andersson MA, Salkinoja-Salonen MS. Properties of Bacillus cereus and other bacilli contaminating biomaterial-based industrial processes. Int J Food Microbiol 2000; 60:231-239.

19. Kotiranta A, Lounatma AK, Haapasa M. Epidemiology and pathogenesis of Bacillus cereus infections. Microbes Infect 2000; 2:189-198.

20. Milagres RCRM. Bacillus cereus em unidade de alimentação e nutrição: avaliação da contaminação do ar e da superfície de trabalho [tese]. Viçosa (MG): Universidade Federal de Viçosa; 2004.

21. Jullien C, Bénézech T, Carpentier B, Lebret V, Faille C. Identification of surface characteristics relevant to the hygienic status of stainless steel for the food industry. J Food Eng 2002; 56:77-87.

22. Kang YJ, Frank FJ. Biological aerosols: A review of airborne contamination and its measurement in dairy processing plants. J. Food Protect. 1989; (52):512-524.

23. Mosso C, Guglielmini N, Lanzetti A. Capacità di $B$. cereus de crescere e produrre enterotossina ed attività di diversi disifettante. Ind Aliment 1996; 35:1073-1075.

24. Soares CM, Valadares GF, Azeredo RM C, Kuayel AY. Contaminação ambiental e perfil toxigênico de Bacillus cereus isolados em serviços de alimentação. Cienc. Rural 2008; (38):504-510.

25. Saccol ALF. Sistematização de ferramenta de apoio para boas práticas em serviço de alimentação [tese]. Santa M aria (RS): Universidade Federal de Santa M aria; 2007.

26. Almeida RCC, Kuaye AY, Serrano AM, Almeida PF. Avaliação e controle da qualidade microbiológica de mãos de manipuladores de alimentos. Rev. Saude Publica 1995; 29(4):290-294.

27. Granum PE. Bacillus cereus and its toxins. Journal of Applied Bacteriology 1994; 76:61-66.

28. M endes RA, Azeredo RM C, Coelho AIM, Oliveira SS, Coelho MSL. Contaminação ambiental por Bacillus cereus em unidade de alimentação e nutrição. Rev. Nutr. 2004; 17(2): 255-261.

29. Guinebretiere $M H, N$ guyen-The $C$. Sources of $B a-$ cillus cereus contamination in a pasteurized zucchini purée processing line, differentiated by two PCR-based methods. FEM S M icrobiology Ecology 2003; 43(2):207-215.

Artigo apresentado em 06/11/2007

Aprovado em 12/05/2008 